\title{
Prevalence and outcome of abnormal blood glucose concentration in critically ill children admitted to Pediatric Emergency Unit at Sohag University Hospital, Egypt
}

\author{
AbdelrahimAbdrabouSadek, Ramadan A Mahmoud, AlyaaRagabSeddik \\ Pediatric Department, Faculty of Medicine, Sohag University, Sohag, Egypt
}

\begin{abstract}
Aims:To determine the frequency and outcome of blood glucose abnormalities, in critically ill children requiring admission to pediatric emergency unit in Sohag University Hospital.

Methods:Prospective observational study, conducted on critically ill children admitted to emergency unit of Sohag University Hospital. Cases were recruited during the study period from September 2015 to April 2016.

Results: The prevalence of hypoglycaemiarepresenting 6\% of all cases. Multivariate analysis of clinical variables associated with hypoglycemia showed thatlast meal $>12$ hours ago, and tachypnea are independent indicators of hypoglycaemia.Hyperglycemia was detected in $15.4 \%$ of all cases.

Patients with abnormal blood glucose measurements had mean length of hospital stay (LOS) $7.7 \pm 10.02$ days, compared to patients with normal blood glucose measurements $8.1 \pm 8.07$ days.PICU admission was found to be more in patients with abnormal blood glucose measurements (23.1\%) compared to patients with normal blood glucose measurements $(3.4 \%)$. Most of patients who had normal blood glucose measurements were discharged well $(77.4 \%)$, whereas $(55.6 \%)$ of patients who were observed to have hypoglycemia died, and $(25.5 \%)$ of patients who were observed to have hyperglycemia died.

Conclusions:Abnormal glucose concentrations are common in critically ill children. Where facilities for blood glucose estimation exist, blood glucose should be measured in all children sick enough to warrant admission, particularly those severely ill or malnourished children and who bear the brunt of mortality.
\end{abstract}

\section{Introduction}

Abnormal

blood glucose concentration is the most common metabolic abnormality in childhood particularly in critically ill children. Children are particularly prone to develop hypoglycaemia in a wide variety of diseases. In resource poor countries, poor nutritional status, infectious diseases, delay in presentation to hospital, and the lack of diagnostic facilities may aggravate hypoglycaemia. Hyperglycemia in non-diabetic patients is common in critically ill children. It does not appear to be associated with a particular diagnostic category but is significantly associated with the severity of illness. Severe hyperglycemia may be associated with complications; this in turn could result in end-organ dysfunction.Hyperglycemia is prevalent in critically ill patients and is associated with poor outcomes, and tight glycemic control may improve morbidity and mortality rates in some settings.

In critically ill patients, the mortality risk associated with 
hypoglycaemia increases linearly with progressive increases in severity of hypoglycaemia. Mortality risk in the hypoglycaemic range develops more steeply than in the hyperglycaemic range.

The main aim of this study was to determine the frequency and outcome of blood glucose abnormalities, in critically ill children requiring admission to pediatric emergency unit in Sohag University Hospital.

\section{Patients and methods}

This work was a prospective observational study, conducted on critically ill children admitted to emergency unit of Sohag University Hospital. Cases were recruited during the study period from September 2015 to April 2016.

Critically ill child was defined as any child who has a life-threatening illness or injury, that can include various acute phases of illness and for which continued parental care or support is required. They included disturbed conscious level $\quad(\mathrm{GCS}<8)$, tachypnea/bradypnea (stand for age), acidotic breathing, Hypothermia $(<36.5 \mathrm{C})$, Hypoxia (oxygen saturation less than $90 \%$ in room air), complicated protein energy malnutrition, severe anemia (haemoglobin level less than $5 \mathrm{gm} / \mathrm{dl}$ ), suspected heart, renal or liver cell failure, suspected intestinal obstruction or shock.

Neonates and diabetic children were excluded. Ethical approval for the study and the investigation was obtained from the Research Committee of Medical Faculty at Sohag University, and written informed consent was obtained from all parents of the children.

\section{Clinical definitions:}

Hypoglycemia and hyperglycemia are defined as blood glucose concentration less than $60 \mathrm{mg} / \mathrm{dl}(\mathbf{1})$ and more than 180 $\mathrm{mg} / \mathrm{dl}$ respectively ${ }^{(\mathbf{2})}$.Severe illness was defined as prostration (inability to sit unsupported, or breast feed) ${ }^{(3)}$, or abnormally deep breathing (Kussmauls respiration) ${ }^{(4)}$.Hypoxia, an oxygen saturation $<90 \%$ in room air; tachypnoea, a respiratory rate of $>40$ per minute in children between 1 and 5 years, and $>50$ per minute in infants greater than 2 months old (5); and severe malnutrition, weight below $3^{\text {rd }}$ centile. Severe anaemia was defined as a haemoglobin of $<5 \mathrm{gm} / \mathrm{dl}^{\left({ }^{(6)}\right.}$

Methods:All eligible cases were subjected to the followings:thorough clinical history including duration since last meal, full clinical examination, random blood glucose measurementby finger pricking technique usingblood glucose device (Bioneme GM300, manufactured by Bionime Corporation. Taichung City, Taiwan,).Follow up random blood glucose measurement if the initial measurement was abnormal were done by finger pricking technique usingblood glucose device.Assessment of hypoxia by pulseoximetery.In addition to routine laboratory investigations according to the expected disease were performed. All cases were followed up for duration of hospital stay, admission to the PICU and its duration and outcome at discharge.

Statistical analysis:Data was analyzed using SPSS (Statistical Package of Social Science) version 22.0. Quantitative data was expressed as means \pm standard deviation, median and range. The data were tested for normality using Kolmogrov-Smirnov test which was significant indicating the use of nonparametric tests as data wasn't normally distributed. The nonparametric Mann-Whitney test was used for comparing two quantitative variables. 
SOHAG MEDICAL JOURNAL

Vol. 21 No.2 July 2017
Prevalence and outcome of abnormal blood glucose Alyaa Ragab Seddik .et al
Kruskal-Wallis test was used for comparison between more than two quantitative variables. Chi-Square test or Fisher's Exact test were used for comparison between qualitative variables. Logistic regression was used to determine factors associated with hypoglycemia and hyperglycemia among the studied population. Graphs were produced using Excel software. $P$ value was considered significant if it was less than 0.05 .

\section{Results}

In this study the total number of patients was 300. Male patients were 168 , and female patients were 132. The mean age of the patients was $23.14 \pm 35.93$ months. The median age was 8 months, range (1.1-192) months. The mean weight was $8.89 \pm 7.04 \mathrm{~kg}$

Prevalence of hypoglycemia:Hypoglycemia was detected in 18 cases representing $6 \%$ of all cases, 10 males $(55.6 \%)$ and 8 females (44.4\%).Multivariate analysis of clinical variables associated with hypoglycemia showed thatlast meal $>12$ hours ago, and tachypnea are independent indicators of hypoglycaemia(Table 1).

Prevalence of hyperglycemia:Hyperglycemia was detected in 47 cases representing 15.4 $\%$ of all cases, 25 males $(53.2 \%)$, and 22 females $(46.8 \%)$.

Patient lengths of hospital stay (LOS), PICU admission, and outcome:Patients with abnormal blood glucose measurements had mean (LOS) 7.7 10.02 days, compared to patients with normal blood glucose measurements $8.1 \pm 8.07$ days (Table 2).PICU admission was found to be more in patients with abnormal blood glucose measurements $(23.1 \%)$ compared to patients with normal blood glucose measurements (3.4\%) (Table 3).

Table (1): Multivariate analysis of clinical variables associated with hypoglycemia

\begin{tabular}{||c|c|c|}
\hline Variables & \multicolumn{2}{|c|}{ Hypoglycemia } \\
\cline { 2 - 3 } & Adjusted OR (CI 95) & P- value \\
\hline & $3.6(1.1-11.6)$ & $\mathbf{0 . 0 3 4}$ \\
Last meal >12 H & $1.5(0.3-7.2)$ & 0.579 \\
Disturbed conscious level & $0.2(0.05-0.9)$ & $\mathbf{0 . 0 2 9}$ \\
Tachypnea & $4.3(0.7-24.9)$ & 0.105 \\
Hypoxia & $1.1(0.2-7.1)$ & 0.950 \\
Malnutrition & $0.0(0.0)$ & 0.998 \\
Anemia & $1.8(0.5-7.1)$ & 0.386 \\
Organ failure & $4.7(0.7-31.8)$ & 0.111 \\
Intestinal obstruction & $0.7(0.2-2.4)$ & 0.532 \\
Shock & & \\
\hline
\end{tabular}

Table (2): length of stay according to blood glucose group $\left(\mathbf{N}_{.}=300\right)$

\begin{tabular}{||l|l|l|l||}
\hline \multirow{2}{*}{ Blood glucose } & LOS & \multirow{2}{*}{ P-value } \\
\cline { 2 - 3 } & Mean \pm SD & Median (Range) & \\
\hline \hline Normal (N.=235) & $8.1 \pm 8.07$ & $6(1-60)$ & \multirow{2}{*}{ 0.02* } \\
\hline Abnormal (N.=65) & $7.7 \pm 10.02$ & $4(1-59)$ & \\
\hline
\end{tabular}

P- value was calculated by Mann-Whitney test *Statistically significant 
Table (3): Admission to PICU according blood glucose.

\begin{tabular}{|l|l|l|l|l|}
\hline \multirow{2}{*}{$\begin{array}{l}\text { PICU } \\
\text { admission }\end{array}$} & \multicolumn{2}{|l|}{ Blood glucose } & Total & P-value \\
\cline { 2 - 4 } & $\begin{array}{l}\text { Normal } \\
\text { N. }(\%)\end{array}$ & $\begin{array}{l}\text { Abnormal } \\
\text { N. (\%) }\end{array}$ & & \\
\hline \hline Yes & $8(3.4 \%)$ & $15(23.1 \%)$ & $23(7.7 \%)$ & \multirow{0}{*}{ 0.000* } \\
\hline No & $227(96.6 \%)$ & $50(76.9 \%)$ & $277(92.3 \%)$ & \\
\hline
\end{tabular}

P- value was calculated by Fisher's Exact Test* Statistically significant

PICU mean (LOS) for patients with abnormal blood glucose measurement was $4.3 \pm 3.3$ days (Table 4).

Table (4): PICU LOS according to blood glucose group (N.=23)

\begin{tabular}{|c|c|c|c|}
\hline \multirow[t]{2}{*}{ Blood glucose } & \multicolumn{2}{|l|}{ PICU LOS } & \multirow[t]{2}{*}{ P-value } \\
\hline & $\begin{array}{ll}\text { Mean } & \pm \\
\text { SD }\end{array}$ & $\begin{array}{l}\text { Median } \\
\text { (Range) }\end{array}$ & \\
\hline Normal (N.=8) & $7.4 \pm 2.3$ & $7(5-11)$ & \multirow{2}{*}{$0.03 *$} \\
\hline Abnormal $(\mathrm{N} .=15)$ & $4.3 \pm 3.3$ & $3(1-10)$ & \\
\hline
\end{tabular}

P- value was calculated by Mann-Whitney test *Statistically significant

Most of patients who had normal blood glucose measurements were discharged well $(77.4 \%)$, whereas $(55.6 \%)$ of patients who were observed to have hypoglycemia died, and (25.5\%) of patients who were observed to have hyperglycemia died (Table 5).

Table (5): Relation between the outcome and blood glucose $\left(\mathbf{N}_{.}=300\right)$

\begin{tabular}{|c|c|c|c|c|}
\hline & \multicolumn{3}{|l|}{ Blood glucose } & \multirow{2}{*}{$\begin{array}{l}\text { P- } \\
\text { value }\end{array}$} \\
\hline & $\begin{array}{l}\text { Hypoglycemic } \\
\text { (18) } \\
\text { No. (\%) }\end{array}$ & $\begin{array}{l}\text { Normal (235) } \\
\text { No. }(\%)\end{array}$ & $\begin{array}{l}\text { Hyperglycemic } \\
\text { (47) } \\
\text { No. }(\%)\end{array}$ & \\
\hline $\begin{array}{l}\text { Good } \\
\text { Yes } \\
\text { No }\end{array}$ & $\begin{array}{l}5(27.8 \%) \\
13(72.2 \%)\end{array}$ & $\begin{array}{l}182(77.4 \%) \\
53(22.6 \%)\end{array}$ & $\begin{array}{l}29(61.7 \%) \\
18(38.3 \%)\end{array}$ & $0.000 *$ \\
\hline $\begin{array}{l}\text { Died } \\
\text { Yes } \\
\text { No } \\
\end{array}$ & $\begin{array}{l}10(55.6 \%) \\
8(44.4 \%) \\
\end{array}$ & $\begin{array}{l}28(11.9 \%) \\
207(88.1 \%)\end{array}$ & $\begin{array}{l}12(25.5 \%) \\
35(74.5 \%)\end{array}$ & $0.000 *$ \\
\hline $\begin{array}{l}\text { Discharged } \\
\text { on demand } \\
\text { Yes } \\
\text { No } \\
\end{array}$ & $\begin{array}{l}2(11.1 \%) \\
16(88.9 \%)\end{array}$ & $\begin{array}{l}12(5.1 \%) \\
223(94.9 \%)\end{array}$ & $\begin{array}{l}12(25.5 \%) \\
35(74.5 \%)\end{array}$ & 0.130 \\
\hline $\begin{array}{l}\text { Referred } \\
\text { Yes } \\
\text { No } \\
\end{array}$ & $\begin{array}{l}0(0 \%) \\
18(100 \%)\end{array}$ & $\begin{array}{l}3(1.3 \%) \\
232(98.7 \%)\end{array}$ & $\begin{array}{l}1(2.1 \%) \\
46(97.9 \%)\end{array}$ & 0.789 \\
\hline $\begin{array}{l}\text { With } \\
\text { squeals } \\
\text { Yes } \\
\text { No }\end{array}$ & $\begin{array}{l}1(5.6 \%) \\
17(94.4 \%)\end{array}$ & $\begin{array}{l}10(4.3 \%) \\
225(95.7 \%)\end{array}$ & $\begin{array}{l}5(10.6 \%) \\
42(89.4 \%)\end{array}$ & 0.206 \\
\hline
\end{tabular}

P- value was calculated by Chi-Square test *Statistically significant 


\section{Discussion}

In our study, more than $21 \%$ of critically ill children admitted to Pediatric Emergency Unit in Sohag University Hospital had an abnormal blood glucose concentration. Hyperglycaemia $(72.3 \%)$ was more common than Hypoglycaemia (27.7\%). This is in agreement -but with different percentages- with the study by Tsultem et al., in which Hyperglycemia (BG $>180 \mathrm{mg} / \mathrm{dL}$ ) occurred in $(45.9 \%)$ of patients. Hypoglycemia (BG <60 $\mathrm{mg} / \mathrm{dL})$ was diagnosed in $(22.35 \%)$ of patients ${ }^{(4)}$.This is compared to the study by Osier et al.,in which more than $10 \%$ of children admitted to a Kenyan rural district hospital had an abnormal blood glucose concentration. Hypoglycaemia $(8.2 \%)$ was more common than hyperglycaemia $(2.7 \%)^{(\mathbf{1}) \text {. }}$

Multivariate analysis of clinical variables associated with hypoglycemia showed thatlast meal $>12$ hours ago, and tachypnea are independent indicators of hypoglycaemia. These two clinical variables are in agreement with Osier et al., study ${ }^{(\mathbf{1})}$.

In our study abnormal blood glucose measurement did not affect neither total length of hospital stay, nor length of stay at PICU, this was in agreement with Tsultem et al., study in which hypoglycemia did not affect PICU length of stay(LOS) ${ }^{(4)}$.This was in contrast to Wintergerst et al., study in which lower minimal glucose levels were associated significantly with longer PICU LOS and total hospital LOS, analysis displayed a significant increase in both PICU and total hospital LOSs with increasing maximal glucose levels ${ }^{(5)}$.

In our study, PICU admission was found to be more in patients with abnormal blood glucose measurements (23.1\%) compared to patients with

normal blood glucose measurements $(3.4 \%)$ ( $P$ value $=0.000)$. In our study, hypoglycemia was strongly associated with increased mortality, as $55.6 \%$ of patients who were hypoglycemic died; this was in agreement -but with different percentage- with Wintergerst et al. study, whofound a strong association between hypo-glycemia and glucose variability and their relationship with LOS and mortality risk.Hypoglycemia was correlated with mortality rates ; $16.5 \%$ of patients with glucose levels < $65 \mathrm{mg} / \mathrm{dL}$ died $^{(5)}$.

Conclusion:Abnormal glucose concentrations are common in critically ill children. Where facilities for blood glucose estimation exist, blood glucose should be measured in all children sick enough to warrant admission, particularly those severely ill or malnourished children and who bear the brunt of mortality.

\section{References}

(1) Osier F H, Berkley J A, Ross A, Sanderson F, Mohammed S, Newton C R.(2003). Abnormal blood glucose concentrations on admission to a rural Kenyan district hospital: prevalence and outcome. Arch Dis Child;88:621-625

(2) E. Vincent S. Faustino, Eliotte L. Hirshberg, and Clifford W. Bogue.(2012). Hypoglycemia in critically ill children.Journal of Diabetes Science and Technology. $2: 6$.

(3) English M, Sauerwein R, Waruiru C, et al.( 2007) Acidosis in severe childhood malaria. Q J Med;90:263-70.

(4) Marsh K, Forster D, Waruiru C, et al.( 1995). Indicators of life-threatening malaria in African children. $\mathrm{N}$ Engl $\mathbf{J}$ Med;332:1399-404. 
(5) WHO.( 1998). Acute respiratory infections in children: case management in small hospitals in developing countries. Mimeographed document no.WHO/ARI 90.5. Geneva: World Health Organisation,.
(6) Newton CRJC, Warn PA, Winstanley PA, et al.( 1997). Contribution of falciparum malaria to severe anemia in Kenyan children. Trop Med Int Health 1997;2:165-78 